\section{What is already known on this topic}

There is widespread aversion to taking drugs and considerable non-adherence to prescribed drug regimens

Little is known about the experience of drug taking in people with chronic multiple morbidity

\section{What this study adds}

People with multiple morbidity expressed ambivalence to taking drugs in several ways: one tension was between the use of a regular drug regimen and a more flexible regimen as people self regulated their drug use in an attempt to gain equilibrium, relief from symptoms, or sense of a "normal" life

Further ambivalence was shown in people expressing reluctance to take drugs and their inability to be "free" of them; also that drugs both enabled respondents to continue to function in social roles and acted as marker for their inability to perform such roles

Drug use was discussed in moral terms to show how people remained competent though seriously challenged by their illnesses, were stoical in their response to illness, and were responsible in their roles as employees and family members
2 Starfield B. New paradigms for quality in primary care. $\mathrm{Br} J$ Gen Pract 2001:51:303-9.

3 Macintyre S, Annandale E, Ecob R, Ford G, Hunt K, Jamieson B, et al. The West of Scotland twenty-07 study: health in the community. In: Martin CJ McQueen DV, eds. Readings for a new public health. Edinburgh: Edinburgh University Press, 1989:56-74.

4 Ford G, Ecob R, Hunt K, Macintyre S, West P. Patterns of class inequality in health through the lifespan: class gradients at 15,35 and 55 years in the West of Scotland. Soc Sci Med 1994;39:1037-50.

5 Hunt K, Wyke S, Walker J. Beyond the burden on illness? What factors predict general practitioner consultations? [abstract].J Epidemiol Community Health 2000;54:786.

6 Wyke S, Hunt K, Walker J, Wilson P. Frequent attendance, socio-economic status and burden or health. An investigation in the West of Scotland. Eur J Gen Pract 2003:9:48-55.

7 Strauss A, Corbin J. Basics of qualitative research:techniques and procedures for developing grounded theory. London: Sage, 1998

8 Donovan JL, Blake DR. Patient non-compliance: deviance or reasoned decision-making? Soc Sci Med 1992;34:507-13.

9 Rogers A, Day JC, Williams B, Randall F, Wood P, Healy D, et al. The meaning and management of neuroleptic medication: a study of patients with a diagnosis of schizophrenia. Soc Sci Med 1998;47:1313-23.

10 Britten N. Lay views of drugs and medicines: orthodox and unorthodox accounts. In: Williams SJ, Calnan M, eds. Modern medicine. Lay perspectives and experiences. London: UCL Press, 1996:48-73.

11 Morgan M. Perceptions and use of anti-hypertensive drugs among cultural groups. In: Williams SJ, Calnan M, eds. Modern medicine. Lay perspectives and experiences. London: UCL Press, 1996:95-116.

12 Benson J, Britten N. Patients' decisions about whether or not to take antihypertensive drugs. BMJ 2002;325:873-6.

13 Britten N. Patients' ideas about medicines: a qualitative study in a general practice population. BrJ Gen Pract 1994;44:465-8.

14 Conrad P. The meaning of medications: another look at compliance. Soc Sci Med 1985;20:29-37.

15 Van der Geest S, Whyte SR. The charm of medicines: metaphors and metonyms. Med Anthropol Q 1989;3:345-67.

(Accepted 1 September 2003)

\title{
Commentary: Does a prescribed treatment match a patient's priorities?
}

Nicky Britten

Institute of Clinical Education,

Peninsula Medical

School, Universities

of Exeter and

Plymouth, St Luke's

Campus, Exeter

EX1 2LU

Nicky Britten

professor

nicky.britten@

pms.ac.uk
Within the past 10 years several studies carried out in different settings have investigated patients' perceptions of prescribed drugs. Most of these studies have been qualitative and relatively small scale. They have all revealed considerable ambivalence about drug taking. This study by Townsend and colleagues confirms the validity of these findings for a community based sample of middle aged people in Scotland with multiple morbidities and provides a rich description of the different aspects of this ambivalence. Most prescribed drugs are taken by elderly people with chronic conditions.

This study also helps to explain quantitative research that has identified core beliefs about the perceived necessity of taking prescribed drugs as well as concerns about potential harms. ${ }^{1}$ It shows the futility of labelling patients as "compliers" or "non-compliers," as the same person may take one drug regularly while altering the dose or frequency of another. The paper shows the ambiguous yet powerful impact of drug taking on people's identity and the efforts that people make to fulfil their family and social obligations. Above all, the paper reveals the centrality of the notion of self regulation of prescribed drugs, in which patients organise their drug taking around their own priorities.

Patients' priorities may therefore be very different from prescribers' priorities, or indeed from the priorities that prescribers assume their patients to have. This paper shows clearly that patients' moral concerns and the demands of their social roles are often more important for them than the alleviation of symptoms or the cure of disease. For people struggling to retain their social identity, the issue of compliance may not be high on their agenda. Clinicians who are trying to give their patients the best evidence about treatment options and to present balanced information about risks and benefits may find it difficult to take this on board.

Clinicians need to engage with patients' priorities in order to understand how prescribed drugs will actually be used once patients have left the consulting room. Researchers developing interventions to improve adherence to treatment may not always engage with patients' priorities, ${ }^{2}$ but clinicians have immediate access to patients' perspectives. The integration, within the consultation, of best evidence and the patients' priorities is at the heart of concordance.

Prescribed drugs may be only one element of an individual's strategy of self care. This paper shows that patients used a range of resources in managing their chronic ill health. They used a minimum-maximum strategy-minimal use of drugs and maximal use of other ways of managing their illnesses. The question for prescribers is not "How can this person use this drug most effectively?" but "How does this drug contribute to this person's self management and the attainment of his or her goals?"

1 Horne R, Weinman J, Hankins M. The beliefs about medicines questionnaire: the development and evaluation of a new method for assessing the cognitive representation. Psychol Health 1999;14:1-24.

2 Haynes RB, Montague P, Oliver T, McKibbon KA, Brouwers MC, Kanani R. Interventions for helping patients to follow prescriptions for medications. Cochrane Database Syst Rev 2000;(2):CD000011.

3 Britten N. Concordance and compliance. In: Jones R, Britten N, CulpepBritten N. Concordance and compliance. In: Jones R, Britten N, Culpep-
per L, Gass D, Grol R, Mant D, et al, eds. Oxford textbook of primary medical care. Oxford: Oxford University Press, (in press). 